\title{
The editor's role in refereeing: a response to Johnston and Pattie
}

\author{
Rob Kitchin \\ NIRSA and Geography, National University of Ireland, Maynooth, County Kildare, Ireland \\ Email: Rob.Kitchin@nuim.ie
}

Revised manuscript received 21 July 2005

\begin{abstract}
We are all very busy, with many things to do in a limited time. But isn't refereeing - like teaching, examining and writing references for colleagues and students - one of the most important and urgent tasks we do? (Johnston and Pattie 2004, 84)
\end{abstract}

In a recent Observation piece, Johnston and Pattie (2004) bemoan the state of refereeing in the discipline, complaining of the length of time it is presently taking for decisions to be made on submissions to journals. Their solution is an appeal to the professional responsibility of referees to undertake timely reviews or to decline to undertake the review quickly so that another referee can be found. They also note that some referees are 'deluged' with requests, so that there is unfair imbalance in refereeing.

As an editor who has been trying to deal with requests for reviews increasingly disappearing into black holes (no response) or having numerous requests turned down or having to badger referees who say they will referee a paper who then do not produce a report, I have been reflecting on what can be done to combat the growing problem of (1) finding referees and (2) getting timely reports. My conclusion is that rather than appealing to academics' sense of professional responsibility (which, as outlined below, I do not believe has declined), editors need to change their strategy for recruiting referees.

There is no doubt that in recent years the number of submissions to the top journals (particularly those listed in ISI - International Scientific Index) has increased, several fold in many cases. This is partly to do with a growth in the number of professional geographers, partly to do with research accountancy exercises that require peer-review papers, and partly to do with pressure on non-Anglo-American authors to publish in ISI journals. Editors therefore have many more papers for which to find referees, yet their main tactic for finding them has changed little, namely seeking the views of a narrow selection of 'experts' in a field, usually those with an established academic profile and known to the editor.

Clearly, an editor is reliant on the advice of 'experts' to make informed decisions. My worry is that the pool of expertise being consulted is too narrow, leading to a large imbalance of refereeing across researchers. Conversely, much expertise within the discipline is little consulted. The result is an unequal expectation as to levels of professional responsibility with, as Johnston and Pattie note, some researchers being swamped by requests for reviews.

To reflect on my own experience, for the past three or four years I have received requests to review between 30 and 50 papers a year (not including my own load as editor of Social and Cultural Geography). I am also receiving requests to review book proposals (4-6 a year) and new journal proposals. Last year, for the first time, I started to decline to referee papers that I thought would be better undertaken by others, and my timeliness in completing reviews has slipped. Despite this, my feeling is that I am performing an adequate professional service and certainly undertaking my fair share of reviewing. A few others I know are dealing with similar loads, and are similarly professional in their approach. They are also now declining reviews because they are inundated and have other jobs to perform. I know of others who set themselves a not unreasonable yearly quota of 10 or 15 papers to review. And if a mid-ranking academic like myself is receiving this number of requests, then I hate to think what the 'big names' are getting. In contrast, I know of many colleagues who receive relatively few, if any, requests and there's the rub. 
The solution, I believe, is for editors to develop a wider sense of expertise and where expertise lies; to significantly broaden the pool of potential reviewers, drawing increasingly from those at the start of their career and those working outside the AngloAmerican tradition. One way to achieve this is for editors to move beyond relying on their own knowledge networks, to draw more widely on their editorial boards and colleagues to identify researchers with sufficient expertise to provide a helpful review. A second is to implement a more systematic referee recruitment strategy. One strategy that Social and Cultural Geography has employed is to ensure that all three referees are not from the same continent. This helps with recruitment, especially from outside the Anglo-American tradition (to complement this SCG has tried to widen the international composition of its editorial board), but also means that a paper speaks to an international audience. A complimentary strategy might be to insist that one of the referees is near the start of their career (within five years of finishing their $\mathrm{PhD}$ ) or to seek at least one referee from a complementary discipline.

While geography is often considered a small discipline compared with others, there are a large number of geographers globally from which to seek reviews. More than 6000 people regularly attend the
Association of American Geographers conference, and yet the Annals of the Association of American Geographers probably employs less than 200 referees in a year - often the same ones that every other journal is trying to employ. The Geography Department Worldwide website (http://univ.cc/geolinks/) lists 1102 geography departments in 90 countries employing several thousand geographers (a large proportion of whom have a proficiency in English). That's a lot of expertise waiting to be utilized, the vast majority of whom will be delighted to perform their professional responsibilities (and similarly to write book reviews, for which it is also becoming difficult to find reviewers).

I do not believe that there is a lack of professional responsibility in the discipline. I do, however, think that there is an imbalance in the distribution of tasks requiring professional responsibility. In conclusion then, I think that editors need to be better at recognizing and trusting expertise across the discipline and distributing refereeing tasks between professional geographers.

\section{Reference}

Johnston R J and Pattie C J 2004 On journal publication and professional responsibilities Area 36 84-5 